\title{
Propafenone-Induced QRS Widening in a Child With Arrhythmogenic Right Ventricular Cardiomyopathy: A Case Report and Literatures Review
}

\author{
Yan-qiu Chu, Ce Wang, Xue-mei Li and Hong Wang * \\ Department of Pediatrics, Shengjing Hospital, China Medical University, Shenyang, China
}

Arrhythmogenic right ventricular cardiomyopathy (ARVC) is a rare cardiac disease in children, and can lead to sudden cardiac death (SCD). Propafenone is classl $\mathrm{C}$ antiarrhythmic medication, and its side effects include cardiovascular compromise in the form of hypotension, bradycardia, ventricular dysrhythmias, QRS widening, and heart block. Propafenone has been reported causing QRS widening, but rarely in

OPEN ACCESS

Edited by:

Arpit Kumar Agarwal,

Baylor College of Medicine,

United States

Reviewed by:

Dominic G. Whittaker,

University of Nottingham,

United Kingdom

Chetan Sharma,

Baylor College of Medicine,

United States

*Correspondence:

Hong Wang

wanghong_64@sina.com

Specialty section: This article was submitted to

Pediatric Cardiology,

a section of the journal

Frontiers in Pediatrics

Received: 17 July 2019 Accepted: 05 October 2020 Published: 30 October 2020

Citation:

Chu Y-q, Wang C, Li X-m and Wang $H$ (2020) Propafenone-Induced QRS

Widening in a Child With

Arrhythmogenic Right Ventricular Cardiomyopathy: A Case Report and

Literatures Review.

Front. Pediatr. 8:481330.

doi: 10.3389/fped.2020.481330 children. In this article, we presented a boy diagnosed with ARVC who meets diagnosis criteria based on typical symptoms, electrocardiograph (ECG), echocardiography (Echo), cardiac magnetic resonance imaging (CMRI), sudden death of first family member, and genetic mutation in desmosomal DSG2 gene. Antiarrhythmic drugs have been used for treating patients with ARVC, by eliminating or decreasing the occurring frequency of arrhythmias. As his ECG showed frequent premature ventricular contractions (PVC), he was prescribed with oral propafenone. One day after the drug treatment, he presented dizziness accompanied with significant QRS widening in ECG. His dizziness was improved when Propafenone dose was reduced, and resolved after sotalol replacement, with ECG recovered to nearly normal state of QRS. Propafenone may lead to QRS widening and increase the risk of ventricular tachycardia, and it may not reduce ARVC associated mortality. This report may serve as a precaution for clinicians when providing cares for ARVC patients.

Keywords: arrhythmogenic right ventricular cardiomyopathy (ARVC), propafenone, sotalol, QRS widen, sudden cardiac death, implantable cardioverter defibrillator

\section{BACKGROUND}

Arrhythmogenic right ventricular cardiomyopathy (ARVC), also known as "arrhythmogenic right ventricular dysplasia (ARVD)," is characterized by ventricular arrhythmias, right ventricular dysfunction, systolic dysfunction, ventricular dilatation, and fibrofatty replacement of myocardium. It is a progressive disease that may result in heart failures. ARVC patients are at a high risk of sudden cardiac death (SCD) (1). ARVC is a rare autosomal dominant disease. It was first described by Dr. Frank Marcus as a progressive hereditary cardiomyopathy with a higher risk of SCD. The prevalence of ARVC in the general population is about $0.02-0.05 \%$ (2). This is one of the main causes of sudden death in young patients due to arrhythmia, and is the leading cause of sudden death in young athletes $(3,4)$. Genetic variations in desmosomal genes, which are responsible for maintaining intercellular adhesion integrity, have been indicated as 
pathogenesis in at least $50 \%$ of ARVC. Dysfunctional desmosomes cause isolation and death of cardiomyocytes, and thus lead to inflammation in the affected myocytes, followed by apoptosis and replacement of fatty fibrous tissue in heart muscle. Ventricular fibrillation (VF) may occur during cell death, while ventricular tachycardia (VT) is associated with fibro-fatty scars. The typical ECG features are VT with left bundle branch block pattern (LBBB), epsilon $(\varepsilon)$ wave and $\mathrm{T}$ wave inversion (5-7), potentially leading to SCD in young patients (8). Disease management is focusing on preventing lethal events such as SCD. Implantable cardioverter defibrillator (ICD) has been proven as a beneficial intervention for reducing SCD significantly in ARVC patients. Despite the lack of evidence in reducing SCD, antiarrhythmic drugs like beta blockers and others have been used in treating patients in USA and the Netherlands. Although they don't reduce SCD, but they manage arrhythmias in these patients (9). However, usage of Antiarrhythmic drugs may increase the risk of arrhythmia in ARVC patients with structural cardiomyopathy; these patients have poor tolerance to severe arrhythmias such as ventricular tachycardia. Antiarrhythmic drugs may cause QRS widening, and QRS widening leads to abnormal electrical activities accompanied by abnormal depolarization and repolarization that provide the basis for the formation of fatal ventricular arrhythmias. Widened QRS has been reported to increase the risk of heart failure and sudden death $(10,11)$. Therefore, clinicians should take precautions when choosing antiarrhythmic drugs for treatment in ARVC patients.

\section{CASE PRESENTATION}

A 10-year-old previous health boy was presented with intermittent dyspnea and chest pain over one month without syncope. His older brother was diagnosed with cardiomyopathy in 2001, characterized with enlarged right ventricle and perforated RV, and suddenly died at 16 years old after running in 2007. His mother occasionally had chest tightness. Her ECG reveals $\mathrm{T}$ wave inversion in leads of III, $\mathrm{V}_{1}, \mathrm{~V}_{2}$, and $\mathrm{V}_{3}$, and her Echo revealed a slight decrease of diastolic function, other measurements are in normal range.

About one month ago, he felt labored dyspnea, and 1 week later he was diagnosed with myocarditis in a local hospital and treated with digoxin, diuretic and myocardium nutrition. Then his symptom released. One week after that, he had dyspnea again and 10 days later was admitted in our pediatric cardiology department. Physical examination showed he was in a general state, Heart Rate 88 bpm, Respiratory Rate 19 bpm, BP 112/72 $\mathrm{mmHg}$, weight $44 \mathrm{~kg}$. No edema on the face and legs, heart sounds strong, without murmur, but rhythm was irregular, auscultation revealed 5 premature beats in $1 \mathrm{~min}$. The liver was $3 \mathrm{~cm}$ below right costal margin. Admission blood test revealed normal cTnI, hs-cTnT, CK-MB mass, and NT-pro BNP. Echo showed the right ventricular (RV) was significantly dilated (RV diameter $31.8 \mathrm{~mm}$ ), RVED/LVED $=0.67$, the wall of the RV became thinner, interwoven reticular muscle fiber structure can be seen in the RV (Figure 1). ECG showed $\varepsilon$ wave and paired
PVC (Figure 2a). Holter showed paired PVC and premature atrial contractions (PAC). Cardiac magnetic resonance imaging (CMRI-in local hospital) revealed a dilated right ventricular outflow tract, thin right ventricular wall with reduced wall motion, and foci of fatty deposit in the right ventricular free wall (Figure 1). Genetic testing finds DSG2 mutation (R49H), which has been indicated to be associated with ARVC. The patient was diagnosed of ARVC.

His father rejected the prescription of betaloc as a treatment for its side effect in reducing sexual function. The patient was treated with aspirin (50 mg, qd po), propafenone (200 mg, $\mathrm{q} 8 \mathrm{~h}$ ), enalapril (5 mg qd), furosemide ( $20 \mathrm{mg} \mathrm{qd}$, oral 4 days a week), and spironolactone (20 mg qd, oral 3 days a week). At admission, his ECG showed QRS was nearly normal, $118 \mathrm{~ms}$ (Figure 2a). QRS duration in this article is measured with $\mathrm{V}_{5}$ andII leads. But on the second day after taking oral propafenone, he developed dizziness and his ECG showed QRS was $158 \mathrm{~ms}$. On third day of oral propafenone, QRS was increased to $170 \mathrm{~ms}$ (Figure 2b). We reduced the dose of propafenone by half, and on next day, QRS was reduced to $120 \mathrm{~ms}$ (Figure 2c). After 1 month treatment, his ECG showed QRS was $164 \mathrm{~ms}$. Therefore, we discontinued propafenone and replaced with sotalol $(80 \mathrm{mg}$, $\mathrm{q} 12 \mathrm{~h}$ ), and gradually increased the dose to $120 \mathrm{mg}$. $\mathrm{q} 12 \mathrm{~h}$. At 3 month of illness, QRS was 114 ms; AECG showed PVC 3001/d with paired PVC. Sotalol was then reduced to $80 \mathrm{mg}$ q12 h. At 6 months of illness, QRS returned to normal-ECG showed QRS was $124 \mathrm{~ms}$ (Figure 2d). The boy felt better, and the symptoms of dyspnea and chest pain were released.

\section{DISCUSSION}

ARVC is one of the common cause of sudden cardiac death in youth $(3,4)$. Therefore, young patients with unexplained syncope, cardiac arrest or arrhythmia should be aware of this disease. Patients can present with a wide spectrum of symptoms. Some patients can be asymptomatic, some patients may have palpitations, dizziness, syncope, heart failure, ventricular arrhythmia, or cardiac arrest. Therefore, the diagnosis of ARVC is relatively challenging. We summarize some of the features of ARVC to help us identify this disease early. i Arrhythmias: usually with LBBB or VT, may also present with frequent PVC. In some patients, ECG can find the electrocardiographic epsilon $(\varepsilon)$ wave. The $\varepsilon$ wave is a low-amplitude spike between the QRS complex and initial portion of the ST segment, and is usually closed to the end of the QRS complex. It is a characteristic ECG waveform in ARVC, and helps clinicians identify possible ARVC earlier (7). ii SCD: The incidence of SCD in ARVC patients under 65 years is $\sim 5 \%$ (12). A possible cause of SCD is due to VT developed into ventricular fibrillation (VF). iii Heart Failure: expansion, thinning of RV may lead to right heart failure, and possible left heart failure (13). In this case, the $\varepsilon$ wave helps us consider ARVC before the final confirmative diagnosis.

ARVC is a rare hereditary disease, and 50\% of ARVC are caused by autosomal dominant genetic mutations, mainly in desmosomal genes, including plakophilin-2(PKP2), plakoglobin (JUP), desmoglein-2(DSG2), desmocollin-2 (DSC2), and 

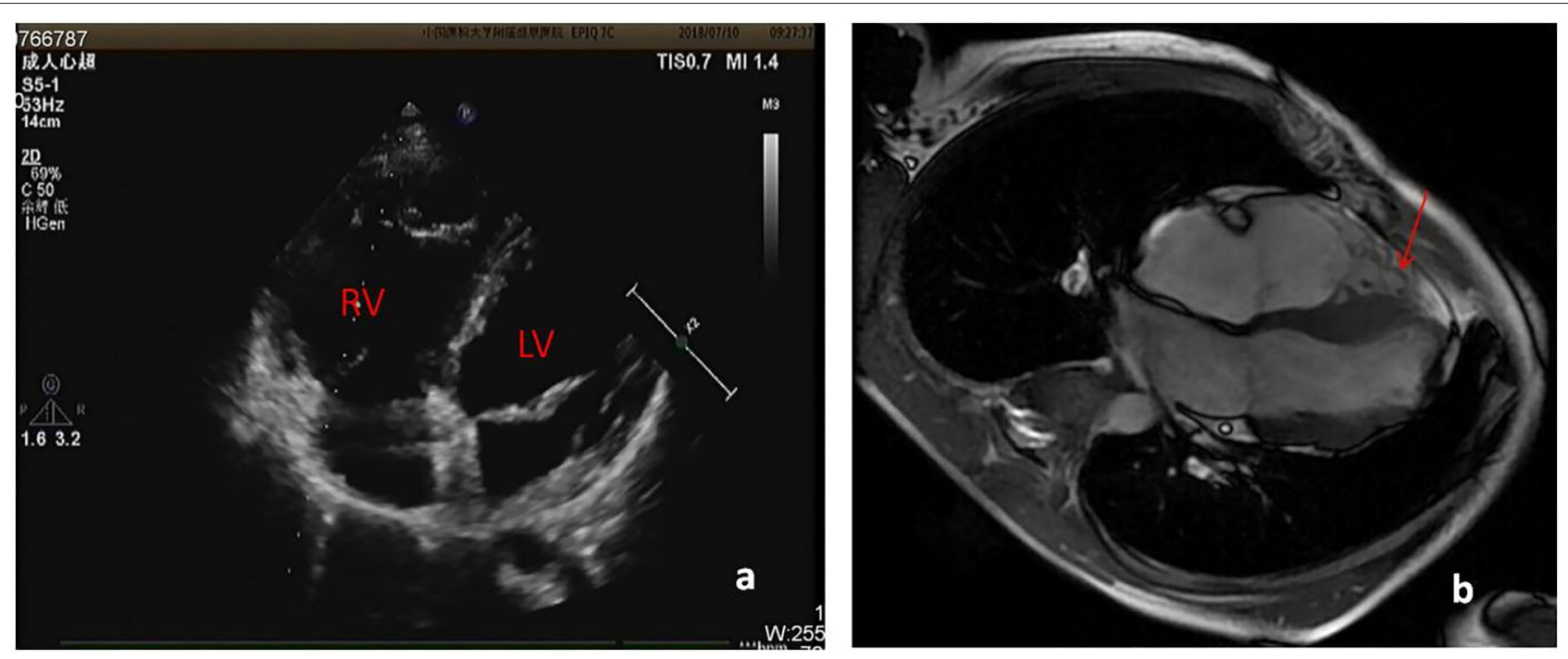

FIGURE 1 | (a) Echo showed RV diameter $31.8 \mathrm{~mm}$, the wall of the RV became thinner. (b) CMRI showed foci of fat in right ventricular free wall.
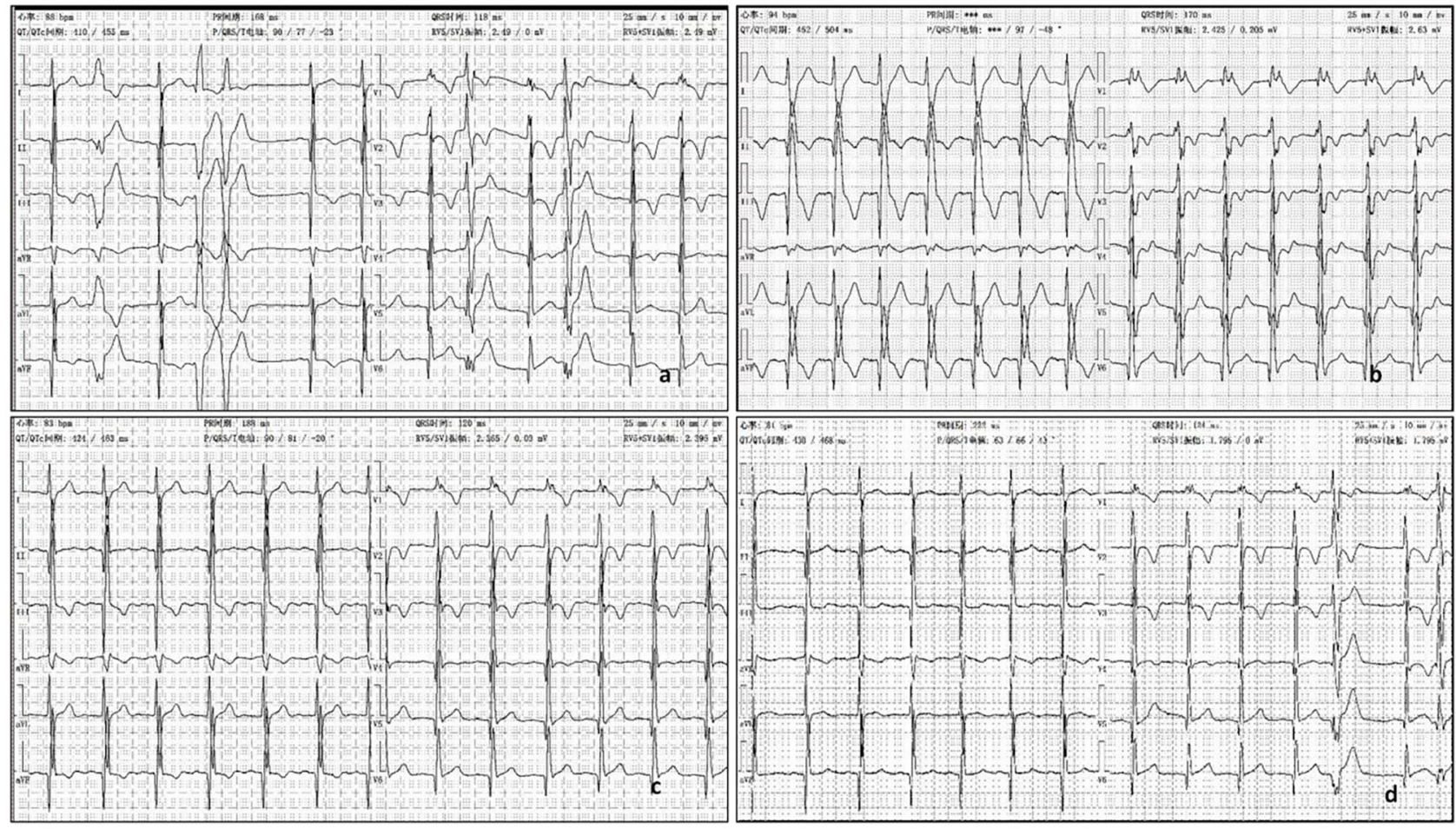

FIGURE 2 | (a) ECG showed $\varepsilon$ wave, paired PVC, QRS = 118 ms. (b) The third day after oral propafenone $200 \mathrm{mg}$, q8h, ECG showed QRS =170 ms, with dizziness. (c) The second day after half oral propafenone $100 \mathrm{mg}$, q8h, ECG showed QRS $=120 \mathrm{~ms}$. (d) After 6 month oral sotalol $80 \mathrm{mg}$, q12h, ECG showed QRS = $124 \mathrm{~ms}$.

desmoplakin (DSP) (14-16). DSG2 mutation has been suggested as a significant pathogenic mutation causing VT and SCD (17). In this case, genetic testing reveals a heterozygous mutation in DSG2 gene, NM_001943.4:c.146G >A/p. $(\mathrm{R} 49 \mathrm{H})$, which is inherited from his mother (Figure 3).
Recent study finds that compound DSG2 mutation variants account for $25 \%$ in the largest Chinese ARVC cohort (18). Chen et al. had reported one pedigree with ARVC linked with DSG2 gene complex heterozygous mutation NM_001943.4:c.146G>A/p. (R49H) (the same mutation in 
The patient Heterozygous variation

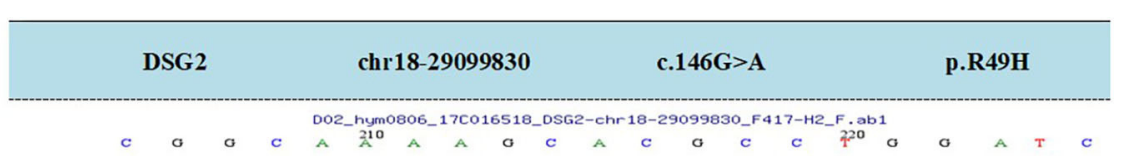

His father

No variation

His mather

Heterozygous variation

His little brother No variation

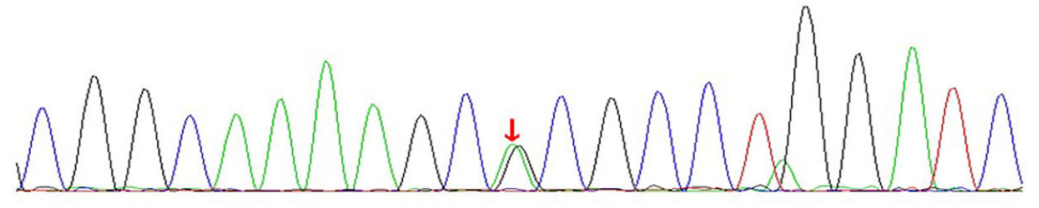

E01_hym0806_17C059864_DSG2-chr18-29099830_F417-H2_F
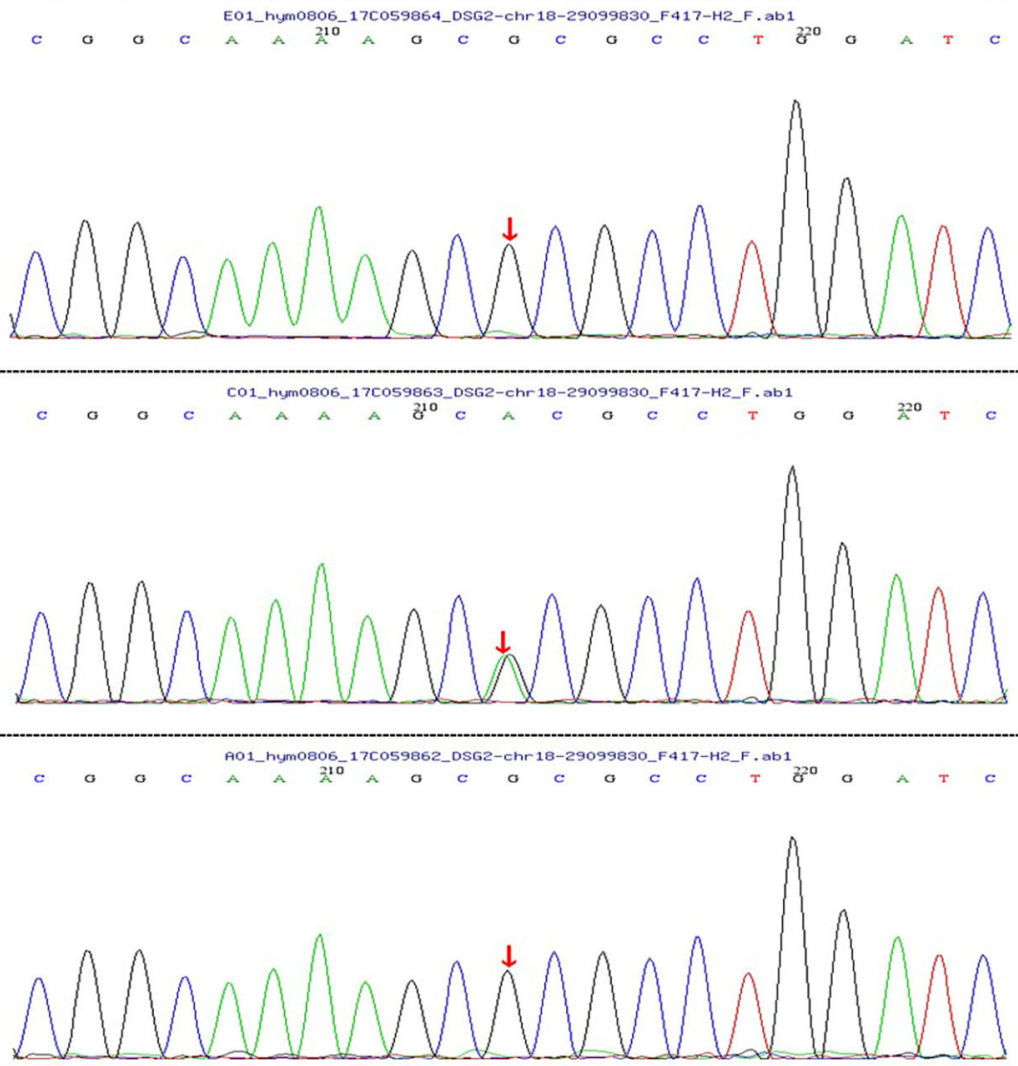
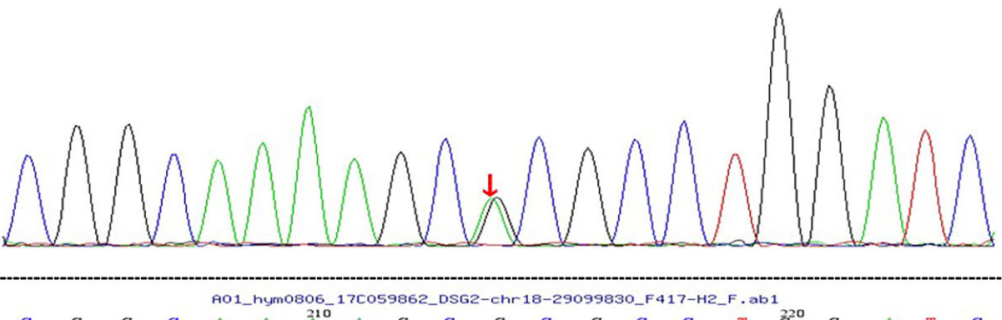

FIGURE 3 | DSG2 gene heterozygous mutation was inherited from his mother.

this boy), and this mutation is considered as a contributing factor to the severe phenotype in ARVC patients (19). One ARVC diagnosis criteria depends on myocardial biopsy showing a fibrofatty replacement of cardiomyocytes, but the procedure is difficult to perform. In 1994, the Task Force reported a diagnostic Criterion based on major and minor criteria including structural, genetic, ECG, arrhythmia and histological factors (20). Modifications were made in 2002, but it was still less sensitive for patients at the early stage $(21,22)$. In 2010, this Criterion was further revised in the Task Force recommendations. New task force criteria use histological, genetic, electrocardiographic, and imaging parameters to classify patients into definite, borderline, and possible diagnostic categories (1). But current clinical trial indicates that many pediatric patients do not meet the current ARVC/D diagnostic criteria, and probably are delayed in diagnosis and treatment (23).

Evidence from clinical trials has not proven antiarrhythmic drugs can reduce SCD. However, antiarrhythmic drug could be theoretically beneficial for ARVC patients by eliminating or decreasing frequent occurrence of arrhythmias (9). Betablockers, particularly sotalol, are conventionally recommended as the first approach in patients with frequent PVC or non-sustained ventricular tachycardia (24). However, a recent 
TABLE 1 | Reported cases of propafenone induced QRS widening.

\begin{tabular}{|c|c|c|c|c|c|c|}
\hline References & Age/sex & Primary disease & Propafenone dose & $\begin{array}{l}\text { Combination } \\
\text { medication }\end{array}$ & Symptoms & ECG \\
\hline Mantovan et al. (27) & 53 y/F & Tachycardia & $1 \mathrm{mg} / \mathrm{kg}$ iv & & & Wide QRS \\
\hline $\begin{array}{l}\text { Brubacher et al. } \\
\text { (28) }\end{array}$ & $73 \mathrm{y} / \mathrm{F}$ & Atrial fibrillation & 300 mg/day po & Propranolol & $\begin{array}{l}\text { Dyspneic and collapsed, } \\
\text { unconscious, no } \\
\text { obtainable blood pressure }\end{array}$ & Wide complex tachycardia \\
\hline Yeung et al. (29) & $72 \mathrm{y} / \mathrm{F}$ & Paroxysmal atrial fibrillation & $2 \star 300$ mg/day po & Verapamil & $\begin{array}{l}\text { Vomiting and diarrhea, } \\
\text { central chest discomfort, } \\
\text { hypotensive, bradycardic }\end{array}$ & $\begin{array}{l}\text { Atrial fibrillation, a QRS } \\
\text { duration of } 166 \mathrm{~ms} \text { and a } \\
\text { corrected QT interval of } \\
536 \mathrm{~ms}\end{array}$ \\
\hline Bayram et al. (30) & $25 \mathrm{y} / \mathrm{M}$ & Atrial fibrillation & 450 mg/day po & & $\begin{array}{l}\text { Lethargic and blood } \\
\text { pressure was not } \\
\text { measurable }\end{array}$ & $\begin{array}{l}\text { Widened QRS interval of } \\
210 \mathrm{~ms} \text {, bradycardia with } \\
\text { first-degree atrioventricular } \\
\text { block }\end{array}$ \\
\hline $\begin{array}{l}\text { Tomcsányi et al. } \\
\text { (31) }\end{array}$ & 84 y/F & $\begin{array}{l}\text { Supraventricular } \\
\text { tachyarrhythmia }\end{array}$ & 3*150 mg/day po & & $\begin{array}{l}\text { Severe, continuous } \\
\text { palpitation, and a blood } \\
\text { pressure of } 80 / 60 \mathrm{mmhg} \text {. }\end{array}$ & $\begin{array}{l}\text { Tachycardia with bizarre, } \\
\text { wide QRS complexes }\end{array}$ \\
\hline
\end{tabular}

M, male; F, female.

report suggests that neither beta-blocker nor sotalol seem to reduce ventricular arrhythmia (25). Therefore, sotalol has been questioned to be used for treating ARVC. In 2015, European Society of Cardiology proposed that beta-blocker titrated to the maximally tolerated dose could be used as the first-line therapy to improve symptoms in patients with frequent PVC and non-sustained ventricular tachycardia (26). We recommended betaloc for this patient. But his father refused to allow the treatment after being informed potential side effects in sexual function. We choose propafenone after thorough consideration. Propafenone is class $I_{C}$ antiarrhythmic medication that has a structure similar to $\beta$-blocker. It blocks the fast-inward sodium current at 0 phase during action potential depolarization, thus causes QRS widening. It slows down the rate of action potential. This prolongs the conduction in myocardium and increases repolarization time, including a slight effect on intraventricular conduction. We input key words "propafenone with wide QRS" when searching in PubMed, there were 5 cases reported in recent 20 years, listed in Table $\mathbf{1}$. However, it is rarely seen in children with normal cardiac structure that propafenone causes QRS widening. In this case the widening effect is significant. We replaced it with sotalol, and widened QRS returned to normal gradually. Antiarrhythmic drugs may increase the risk of arrhythmia in cardiomyopathy patients with abnormal cardiac structure. These patients have poor tolerance to severe arrhythmias such as ventricular tachycardia. Antiarrhythmic drugs may cause QRS widening, and QRS widening leads to abnormal electrical activities accompanied by abnormal depolarization and repolarization that provide the basis for the formation of fatal ventricular arrhythmias. Widened QRS has been reported to increase the risk of heart failure and sudden death $(10,11)$. Therefore, clinicians should take precaution when choosing antiarrhythmic drugs in these patients. In ARVC patients who meet the criteria, the right ventricle muscle is gradually replaced with adipose and fibrous tissue, which often leads to ventricular dilatation. Once QRS widening occurs, we should pay great attention as it can easily cause ventricular tachycardia in those patients.

At present, prevention of the occurrence of fatal events is the main goal in ARVC patient management, and this includes ICD (32). Currently, ICD placement is an effective intervention to reduce mortality in ARVC patients. Other treatment managements including antiarrhythmic drugs, radiofrequency ablation (RFA), cardiac transplantation, and lifestyle changes have not shown significant benefits in reducing mortality (3335). ICD placement has been used as primary or secondary prevention for ARVC patients $(36,37)$. For patients with LV dysfunction or severe RV systolic dysfunction, with a family history of sudden death, or with syncope but not excluding possibilities caused by VT or VF, and for patients with higher expectation of survival, ICD placement can be considered as the primary intervention (38).

\section{CONCLUSION}

Propafenone may lead to QRS widening and increase the risk of ventricular tachycardia occurrence. This may be one of the reasons that propafenone does not reduce the mortality in ARVC patients.

\section{ETHICS STATEMENT}

We have obtained written consent from the patient's parents in this case report.

\section{AUTHOR CONTRIBUTIONS}

Y-qC and HW: conception or design of the work. CW and $\mathrm{X}-\mathrm{mL}$ : case collection. $\mathrm{Y}-\mathrm{qC}$ and $\mathrm{HW}$ : case analysis and interpretation. Y-qC: drafting the article. HW: critical revision of the article. All authors contributed to the article and approved the submitted version. 


\section{REFERENCES}

1. Marcus FI, McKenna WJ, Sherrill D, Basso C, Bauce B, Bluemke DA, et al. Diagnosis of arrhythmogenic right ventricular cardiomyopathy/dysplasia: proposed modification of the task force criteria. Circulation. (2010) 121:153341. doi: 10.1161/CIRCULATIONAHA.108.840827

2. Kiès P, Bootsma M, Bax J, Schalij MJ, van der Wall EE. Arrhythmogenic right ventricular dysplasia/cardiomyopathy: screening, diagnosis, and treatment. Heart Rhythm. (2006) 3:225-34. doi: 10.1016/j.hrthm.2005.10.018

3. Basso C, Corrado D, Thiene G. Cardiovascular causes of sudden death in young individuals including athletes. Cardiol Rev. (1999) 7:127-35. doi: 10.1097/00045415-199905000-00009

4. Tabib A, Loire R, Chalabreysse L, Meyronnet D, Miras A, Malicier D, et al. Circumstances of death and gross and microscopic observations in a series of 200 cases of sudden death associated with arrhythmogenic right ventricular cardiomyopathy and/or dysplasia. Circulation. (2003) 108:3000-5. doi: 10.1161/01.CIR.0000108396.65446.21

5. Dalal D, Nasir K, Bomma C, Prakasa K, Tandri H, Piccini J, et al. Arrhythmogenic right ventricular dysplasia: a United States experience. Circulation. (2005) 112:3823-32. doi: 10.1161/CIRCULATIONAHA.105.542266

6. Nava A, Bauce B, Basso C, Muriago M, Rampazzo A, Villanova C, et al. Clinical profile and long-term follow-up of 37 families with arrhythmogenic right ventricular cardiomyopathy. J Am Coll Cardiol. (2000) 36:2226-33. doi: 10.1016/S0735-1097(00)00997-9

7. Fontaine G, Frank R, Guiraudon G, Pavie A, Tereau Y, Chomette G, et al. Significance of intraventricular conduction disorders observed in arrhythmogenic right ventricular dysplasia. Arch Mal Coeur Vaiss. (1984) 77:872-9.

8. James CA, Calkins H. Update on Arrhythmogenic Right Ventricular Dysplasia/ Cardiomyopathy (ARVD/C). Curr Treat Options Cardiovasc Med. (2013) 15:476-87. doi: 10.1007/s11936-013-0251-8

9. Nasir K, Bomma C, Tandri H, Roguin A, Dalal D, Prakasa K, et al. Electrocardiographic features of arrhythmogenic right ventricular dysplasia/cardiomyopathy according to disease severity: a need to broaden diagnostic criteria. Circulation. (2004) 110:1527-34. doi: 10.1161/01.CIR.0000142293.60725.18

10. Zimetbaum PJ, Buxton AE, Batsford W, Fisher JD, Hafley GE, Lee KL, et al. Electrocardiographic predictors of arrhythmic death and total mortality in the multicenter unsustained tachycardia trial. Circulation. (2004) 110:766-9. doi: 10.1161/01.CIR.0000139311.32278.32

11. Shamim W, Francis DP, Yousufuddin M, Varney S, Pieopli MF, Anker SD, et al. Intraventricular conduction delay: a prognostic marker in chronic heart failure. Int J Cardiol. (1999) 70:171-8. doi: 10.1016/S0167-5273(99)00077-7

12. Gemayel C, Pelliccia A, Thompson PD. Arrhythmogenic right ventricular cardiomyopathy. J Am Coll Cardiol. (2001) 38:1773-81. doi: 10.1016/S0735-1097(01)01654-0

13. Norman MW, McKenna WJ. Arrhythmogenic right ventricular cardiomyopathy: perspectives on disease. Z Kardiol. (1999) 88:550-4. doi: 10.1007/s003920050324

14. Bhonsale A, Groeneweg JA, James CA, Dooijes D, Tichnell C, Jongbloed JD, et al. Impact of genotype on clinical course in arrhythmogenic right ventricular dysplasia/cardiomyopathy-associated mutation carriers. Eur Heart J. (2015) 36:847-55. doi: 10.1093/eurheartj/ehu509

15. Cox MG, van der Zwaag PA, van der Werf C, van der Smagt JJ, Noorman M, Bhuiyan ZA, et al. Arrhythmogenic right ventricular dysplasia/cardiomyopathy: pathogenic desmosome mutations in index-patients predict outcome of family screening: Dutch arrhythmogenic right ventricular dysplasia/cardiomyopathy genotypephenotype follow-up study. Circulation. (2011) 123:2690-700. doi: 10.1161/CIRCULATIONAHA.110.988287

16. Basso C, Corrado D, Marcus FI, Nava A, Thiene G. Arrhythmogenic right ventricular cardiomyopathy. Lancet. (2009) 373:1289-300. doi: 10.1016/S0140-6736(09)60256-7

17. Lin Y, Huang J, He S, Feng R, Zhong Z, Liu Y, et al. Case report of familial sudden cardiac death caused by a DSG2 p.F531C mutation as genetic background when carrying with heterozygous KCNE5 p.D92E/E93X mutation. BMC Med Genet. (2018) 19:148. doi: 10.1186/s12881-018-0580-2
18. Chen L, Rao M, Chen X, Chen K, Ren J, Zhang N, et al. A founder homozygous DSG2 variant in East Asia results in ARVC with full penetrance and heart failure phenotype. Int J Cardiol. (2019) 274:263-70. doi: 10.1016/j.ijcard.2018.06.105

19. Chen X, Peng H, Zheng C, Zhang H, Yan C, Ma H, et al. Two pedigrees with arrhythmogenic right ventricular cardiomyopathy linked with R49H and F531C mutation in DSG2. Hum Genome Var. (2019) 6:38. doi: 10.1038/s41439-019-0069-3

20. McKenna WJ, Thiene G, Nava A, Fontaliran F, Blomstrom-Lundqvist C, Fontaine G, et al. Diagnosis of arrhythmogenic right ventricular dysplasia/cardiomyopathy. Task force of the working group myocardial and pericardial disease of the European Society of cardiology and of the scientific council on cardiomyopathies of the International Society and Federation of Cardiology. Br Heart J. (1994) 71:215-8. doi: 10.1136/hrt.71.3.215

21. Hamid MS, Norman M, Quraishi A, Firoozi S, Thaman R, Gimeno JR, et al. Prospective evaluation of relatives for familial arrhythmogenic right ventricular cardiomyopathy/dysplasia reveals a need to broaden diagnostic criteria. J Am Coll Cardiol. (2002) 40:1445-50. doi: 10.1016/S0735-1097(02)02307-0

22. te Riele AS, James CA, Rastegar N, Bhonsale A, Murray B, Tichnell C, et al. Yield of serial evaluation in at-risk family members of patients with ARVD/C. J Am Coll Cardiol. (2014) 64:293-301. doi: 10.1016/j.jacc.2014.04.044

23. Deshpande SR, Herman HK, Quigley PC, Shinnick JK, Cundiff CA, Caltharp S, et al. Arrhythmogenic right ventricular cardiomyopathy/dysplasia (ARVC/D): review of 16 pediatric cases and a proposal of modified pediatric criteria. Pediatr Cardiol. (2016) 37:646-55. doi: 10.1007/s00246-015-1327-x

24. Wichter T, Borggrefe M, Haverkamp W, Chen X, Breithardt G. Efficacy of antiarrhythmic drugs in patients with arrhythmogenic right ventricular disease. Results in patients with inducible and noninducible ventricular tachycardia. Circulation. (1992) 86:29-37. doi: 10.1161/01.CIR.86.1.29

25. Marcus GM, Glidden DV, Polonsky B, Zareba W, Smith LM, Cannom DS, et al. Efficacy of antiarrhythmic drugs in arrhythmogenic right ventricular cardiomyopathy: a report from the North American ARVC Registry. J Am Coll Cardiol. (2009) 54:609-15. doi: 10.1016/j.jacc.2009.04.052

26. Priori SG, Blomström-Lundqvist C, Mazzanti A, Blom N, Borggrefe $\mathrm{M}$, Camm J, et al. ESC Guidelines for the management of patients with ventricular arrhythmias and the prevention of sudden cardiac death: The Task Force for the Management of Patients with Ventricular Arrhythmias and the Prevention of Sudden Cardiac Death of the European Society of Cardiology (ESC)Endorsed by: Association for European Paediatric and Congenital Cardiology (AEPC). Europace. (2015) 17:1601-87. doi: 10.1093/europace/euv319

27. Mantovan R, Verlato R, Corrado D, Buia G, Haissaguerre M, Shah DC. Orthodromic tachycardia with atrioventricular dissociation: evidence for a nodoventricular (Mahaim) fiber. Pacing Clin Electrophysiol. (2000) 23:276-9. doi: 10.1111/j.1540-8159.2000.tb00813.x

28. Brubacher J. Bicarbonate therapy for unstable propafenoneinduced wide complex tachycardia. CJEM. (2004) 6:349-56. doi: 10.1017/S1481803500009635

29. Yeung A, Shanks D, Parwana H, Gin K. Acute propafenone toxicity after two exposures at standard dosing. Can J Cardiol. (2010) 26:209-10. doi: 10.1016/S0828-282X(10)70402-5

30. Bayram Z, Güner A, Dogan C, Yilmaz F, Özdemir N. Severe cardiac toxicity following alcohol intake in a patient using therapeutic dose of propafenone. Turk Kardiyol Dern Ars. (2017) 45:752-4. doi: 10.5543/tkda.2017.84553

31. Tomcsányi J, Tomcsányi K. Wide QRS alternans caused by propafenone toxicity. Acta Cardiol. (2019) 74:82-3. doi: 10.1080/00015385.2018.14 27304

32. Corrado D, Wichter T, Link MS, Hauer R, Marchlinski F, Anastasakis A, et al. Treatment of arrhythmogenic right ventricular cardiomyopathy/dysplasia: an international task force consensus statement. Eur Heart J. (2015) 36:3227-37. doi: $10.1093 /$ eurheartj/ehv162

33. Schinkel AF. Implantable cardioverter defibrillators in arrhythmogenic right ventricular dysplasia/cardiomyopathy: patient outcomes, incidence of appropriate and inappropriate interventions, and complications. Circ Arrhythm Electrophysiol. (2013) 6:562-8. doi: 10.1161/CIRCEP.113.000392

34. Tedford RJ, James C, Judge DP, Tichnell C, Murray B, Bhonsale A, et al. Cardiac transplantation in arrhythmogenic right ventricular 
dysplasia/cardiomyopathy. J Am Coll Cardiol. (2012) 59:289-90. doi: 10.1016/j.jacc.2011.09.051

35. James CA, Bhonsale A, Tichnell C, Murray B, Russell SD, Tandri $\mathrm{H}$, et al. Exercise increases age-related penetrance and arrhythmic risk in arrhythmogenic right ventricular dysplasia/cardiomyopathy-associated desmosomal mutation carriers. J Am Coll Cardiol. (2013) 62:1290-7. doi: 10.1016/j.jacc.2013.06.033

36. Corrado D, Leoni L, Link MS, Della Bella P, Gaita F, Curnis A, et al. Implantable cardioverter-defibrillator therapy for prevention of sudden death in patients with arrhythmogenic right ventricular cardiomyopathy/dysplasia. Circulation. (2003) 108:3084-91. doi: 10.1161/01.CIR.0000103130.33451.D2

37. Corrado D, Calkins H, Link MS, Leoni L, Favale S, Bevilacqua M, et al. Prophylactic implantable defibrillator in patients with arrhythmogenic right ventricular cardiomyopathy/dysplasia and no prior ventricular fibrillation or sustained ventricular tachycardia. Circulation. (2010) 122:1144-52. doi: 10.1161/CIRCULATIONAHA.109.913871
38. Idris A, Shah SR, Park K. Right ventricular dysplasia: management and treatment in light of current evidence. J Community Hosp Intern Med Perspect. (2018) 8:101-6. doi: 10.1080/20009666.2018.14 72513

Conflict of Interest: The authors declare that the research was conducted in the absence of any commercial or financial relationships that could be construed as a potential conflict of interest.

Copyright () $2020 \mathrm{Chu}$, Wang, Li and Wang. This is an open-access article distributed under the terms of the Creative Commons Attribution License (CC BY). The use, distribution or reproduction in other forums is permitted, provided the original author(s) and the copyright owner(s) are credited and that the original publication in this journal is cited, in accordance with accepted academic practice. No use, distribution or reproduction is permitted which does not comply with these terms. 